\title{
Interleukin-1 receptor-related protein ST2 suppresses the initial stage of bleomycin- induced lung injury
}

\author{
N. Mato*, M. Fujii\#, Y. Hakamatađ, E. Kobayashi', A. Sato ${ }^{\S}$, M. Hayakawa\#", \\ H. Ohto-Ozaki ${ }^{\#}$, M. Bando*, S. Ohno*, S. Tominaga ${ }^{\#}$ and Y. Sugiyama*
}

ABSTRACT: Acute lung injury has a range of causes, and occasionally leads to lethal respiratory failure. Despite advances in treatment, acute lung injury continues to have a high mortality rate, and thus a new therapeutic approach is needed. ST2 is an interleukin (IL)-1 receptor-related protein, and its expression is induced by various inflammatory responses. Recently, ST2 has been speculated to exert anti-inflammatory effects; therefore, we investigated the role of the ST2 in the murine model of acute lung injury.

To elucidate the function of ST2 in vivo, mice that transiently overexpressed ST2 protein were prepared using the hydrodynamic gene transfer method, and lung injury was induced by intratracheal administration of bleomycin.

In bleomycin-treated ST2-overexpressing mice, the increase of neutrophils in the bronchoalveolar lavage fluid (BALF) was markedly suppressed. Additionally, the levels of tumour necrosis factor- $\alpha$ and IL-6, as well as the concentration of albumin, in BALF were reduced compared with those of controls. Furthermore, the pulmonary architecture in ST2-overexpressing mice remained almost normal, and the survival rate was significantly improved.

From these results, we concluded that ST2 has the potential to suppress the initial stage of acute lung injury, and therefore it may be a useful reagent for the treatment of acute lung injury.

KEYWORDS: Acute lung injury, bleomycin, hydrodynamic injection, ST2

A cute lung injury (ALI) can be triggered by various stimuli, including drugs, sepsis and trauma [1]. It is characterised by epithelial and endothelial damage, and is followed by destruction of the alveolar capillaryepithelial barrier. The increased permeability of pulmonary capillary vessels allows flooding of inflammatory cells, enables plasma proteins to enter the lung and results in a disturbance of gas exchange $[1,2]$. The mortality rate of ALI patients remains high (40-60\%) despite the numerous attempts that have been made to develop new therapies [2]. For the treatment of ALI, factors such as mechanical ventilation settings, oxygen concentration maintenance and the management of fluid balance have been extensively investigated, and new devices and techniques have led to important improvements. However, in spite of these efforts, an effective therapy to attenuate the inflammatory process in ALI has not been established.
TOMINAGA [3] originally identified the ST2 (interleukin (IL)-1 receptor-related) gene as an earlyresponse gene in mouse fibroblasts. The ST2 gene generates at least four different gene products, the soluble secreted form (ST2), the transmembrane form (ST2L) and two variant forms (ST2V and ST2LV), by alternative splicing [4]. Recently, a specific ligand for ST2L was discovered and named IL-33 by SCHMITZ et al. [5]. ST2 has been known to be related to various disorders in humans and an increase of serum ST2 has been reported in conditions such as septic shock [6], severe trauma [6], bronchial asthma [7] and idiopathic pulmonary fibrosis, especially in acute exacerbation [8]. Several experimental studies have suggested that the induction of ST2 by various inflammatory stimuli may confer protection against inflammatory damage. For example, it has been reported that pre-treatment with ST2 resulted in an attenuation of pro-inflammatory cytokines and an enhanced survival rate in a

\section{AFFILIATIONS}

*Division of Pulmonary Medicine, Dept of Medicine, Jichi Medical University,

${ }^{\#}$ Dept of Biochemistry, Jichi Medical University,

${ }^{+}$Division of Organ Replacement Research, Center for Molecular Medicine, Jichi Medical University, and,

${ }^{\S}$ Dept of Dermatology, Jichi Medical University, Tochigi, and

"Dept of Basic Science, School of Veterinary Nursing and Technology, Nippon Veterinary and Life Science University, Musashino-shi, Japan.

CORRESPONDENCE

Y. Sugiyama

Division of Pulmonary Medicine,

Jichi Medical University,

3311-1 Yakushiji,

Shimotsuke-Shi,

Tochigi 329-0498,

Japan.

Fax: 81285443586

E-mail: sugiyuki@jichi.ac.jp

Received:

July 072007

Accepted after revision:

January 132009

SUPPORT STATEMENT

The present study was supported in part by a grant from the Center of Excellence in the 21st Century Program of the Ministry of Education, Culture, Sports, Science, and Technology of Japan (Tokyo, Japan).

STATEMENT OF INTEREST

None declared.

European Respiratory Journal Print ISSN 0903-1936

Online ISSN 1399-3003 
mouse endotoxin shock model [9]. ST2 has also been shown to inhibit degradation of inhibitor on nuclear factor- $\mathrm{K} B$ and suppress lipopolysaccharide-induced IL-6 production in THP-1 cells [10]. Additionally, in a collagen-induced arthritis model, it was demonstrated that ST2 suppressed the production of inflammatory cytokines and significantly attenuated the disease [11].

Taken together, these findings suggest that it is worthwhile to assess the therapeutic potential of ST2 as an anti-inflammatory agent in vivo. In the current study, ST2-overexpressing mice were prepared by the hydrodynamic gene transfer method, and the effects of ST2 on bleomycin-induced lung injury were investigated. Based on the anti-inflammatory effects of ST2, it was hypothesised that its in vivo overexpression would ameliorate bleomycin-induced lung injury in mice.

\section{MATERIALS AND METHODS \\ Mice}

Male C57BL/6 mice, aged 7-8 weeks (body weight 18-22 g), were purchased from Japan SLC (Hamamatsu, Japan). Mice were maintained under standard conditions and fed rodent chow and water ad libitum. The research proposal was reviewed by the animal ethical committee of Jichi Medical University (permission No. 152; Tochigi, Japan), and all experiments were performed in accordance with the Jichi Medical University Guide for Laboratory Animals, based on the Helsinki convention for the use and care of animals. The number of mice employed in the different experiments is described in the relevant figure legends.

\section{Plasmids}

pCAGGS and pCAGGS-LacZ were kindly provided by J. Miyazaki (Osaka University, Osaka, Japan) and T. Murakami (Jichi Medical University, Tochigi, Japan), respectively. pCAGGS was an efficient expression vector driven by the chicken $\beta$-actin promoter, and pCAGGS-LacZ was constructed by insertion of the $\beta$-galactosidase reporter gene into pCAGGS. pCAGGS-mST2 was constructed by insertion of mouse ST2 (mST2) cDNA into the Xho1 restriction site of pCAGGS. The European Molecular Biology Laboratory/GeneBank accession number for the nucleotide sequence mST2 is Y07519. mST2 cDNA was originally isolated from the cDNA library of BALB/c-3T3 cells after growth stimulation with serum [12]. First, the Hinc 2 fragment of mST2 cDNA containing the entire coding region $(1,582 \mathrm{bp})$ was inserted into the $\mathrm{Xba1}$ site of the pEF-BOS plasmid (pEF-BOS-mST2) using an Xba1 linker. Secondly, the fragment of mST2 was obtained from pEFBOS-mST2 by digestion with Xba1, and ligated with the Xho1 linker. Thirdly, the pCAGGS plasmid was digested with Xho1 and finally the mST2 fragment, digested with Xho1, was inserted. Plasmids were purified with a Plasmid Maxi Kit (Qiagen, Valencia, CA, USA). The pGL3 control vector containing a firefly luciferase reporter gene was purchased from Promega (Madison, WI, USA).

\section{Cell culture and in vitro transfection}

To confirm that the constructed plasmid was appropriate for producing soluble recombinant ST2 protein, human embryonic kidney (HEK) 293T cells were cultured and transfected with pCAGGS and pCAGGS-mST2. HEK 293T cells were kindly provided by T. Kasahara (Kyoritsu University of Pharmacy,
Tokyo, Japan), and were cultured in Dulbecco's modified Eagle's medium (Sigma-Aldrich, St Louis, MO, USA) containing 10\% (volume/volume (v/v)) foetal bovine serum (Thermo Trace, Melbourne, Australia). The amount of plasmid was $10 \mu \mathrm{g}$, and transfection was carried out by the calcium phosphate precipitation method.

\section{Western blotting}

$20 \mathrm{~h}$ after the transfection of pCAGGS and pCAGGS-mST2, the culture medium was collected, digested with $N$-Glycosidase-F (Roche, Indianapolis, IN, USA), and subjected to sodium dodecyl sulphate-polyacrylamide gel electrophoresis and immnunoblotting, as described previously [12]. In brief, proteins were separated electrophoretically with $10 \%$ polyacrylamide gel and transferred to an Immobilon-P membrane (Millipore, Bedford, MA, USA) at $100 \mathrm{~mA}$ for $1 \mathrm{~h}$. Immunoblotting was performed with rabbit anti-mouse ST2 polyclonal antibody ( $\times 1000$ dilution) against the recombinant ST2 protein from Escherichia coli, and after incubation for $1 \mathrm{~h}$ at room temperature. Then the membrane was incubated for $0.5 \mathrm{~h}$ with anti-rabbit immunoglobulin (Ig) G-horseradish peroxidase $(\mathrm{HRP} ; \times 5000$ dilution; Jackson Immunoresearch, West Grove, PA, USA) as a secondary antibody, and the protein band was visualised by the ECL system (Amersham Bioscience, Amersham, UK).

\section{In vivo gene transfer}

Plasmid vectors were delivered into mice by hydrodynamic injection, which is an efficient in vivo method of gene transfer. Plasmid DNA was diluted in sterile saline, and the final volume was adjusted to $6.3 \%$ of total body weight [13]. Under mild anesthesia with diethyl ether, mice were injected with the plasmid solution through the dorsal penile vein in 5-8 s, using a 26-gauge needle. The amount of plasmid vector was appropriately chosen in each experiment.

To evaluate liver damage, mice were sacrificed and blood was collected at 24 and $48 \mathrm{~h}$ after the hydrodynamic gene transfer. Serum aspartate aminotransferase (AST) and alanine aminotransferase (ALT) levels were assayed by the Japan Society of Clinical Chemistry transferase method using an AST kit and ALT kit (Wako, Osaka, Japan) by the Clinical Analyzer Model 7180 (Hitachi High-Technologies Co., Tokyo, Japan).

\section{In vivo bioluminescent imaging and luciferase asssay}

In order to examine the expression and distribution of the transgene after hydrodynamic injection, in vivo bioimaging was performed. Mice were injected with $20 \mu \mathrm{g}$ of pGL3 control vector or saline as a control, and $24 \mathrm{~h}$ after the injection, were anaesthetised with a mixture of ketamine and xylazine. Dluciferin (potassium salt; Biosynth, Staad, Switzerland) was injected into the peritoneal cavity of mice at $2 \mathrm{mg} \cdot \mathrm{kg}^{-1}$. After $5 \mathrm{~min}$, luciferase activity was detected from the ventral surface using a noninvasive bioimaging system (IVIS; Xenogen, Alameda, CA, USA) [13, 14].

Furthermore, to precisely quantify luciferase activity in individual organs, the liver (quadrate lobe), right lung, heart, kidney and spleen were excised from mice $24 \mathrm{~h}$ after the hydrodynamic gene transfer. $1 \mathrm{ml}$ of Passive Lysis Buffer (Promega) was added to the organs and homogenised with a Polytron homogenizer (Kinematica, Littau, Switzerland). 
Homogenates were frozen $\left(-80^{\circ} \mathrm{C}\right)$ and thawed twice and then centrifuged for $10 \mathrm{~min}$ at $13,000 \times g$ at $4^{\circ} \mathrm{C}$. The total protein content of the supernatants was determined by the Bradford method with protein assay dye reagent (Bio-Rad, Hercules, CA, USA) with calibration using bovine serum albumin (Sigma-Aldrich). For the luciferase assay, $10 \mu \mathrm{L}$ of supernatant homogenate was mixed with $50 \mu \mathrm{L}$ of luciferase assay reagent II (Promega), and luciferase activity was measured by a luminometer (Lumat LB9507; Berthold Technologies, Bad Wildbad, Germany). The data were presented as the relative light units per total protein content.

\section{Detection of Lac Z protein}

For visual confirmation of the gene expression in each organ, $20 \mu \mathrm{g}$ of pCAGGS-Lac $Z$ and the same dose of pCAGGS, as a control, were introduced. $48 \mathrm{~h}$ after the hydrodynamic injection, mice were sacrificed and each organ (liver and lung) was excised and fixed with a mixture of $0.2 \%(\mathrm{v} / \mathrm{v})$ glutaraldehyde and $1 \%(\mathrm{v} / \mathrm{v})$ formaldehyde for $1 \mathrm{~h}$ at $4{ }^{\circ} \mathrm{C}$, and the samples were then stained with $1 \mathrm{mg} \cdot \mathrm{mL}^{-1}$ of 5-bromo-4-chloro-3indolyl- $\beta$-D-galactopyranoside (X-gal; Sigma-Aldrich).

\section{ST2-overexpressing mice}

In order to prepare ST2-overexpressing mice, pCAGGS-mST2 was introduced by hydrodynamic injection, and pCAGGS was used as a control. Starting $12 \mathrm{~h}$ after the gene transfer, blood was collected from the tail vein and the concentration of plasma ST2 protein was confirmed. Concurrently, bronchoalveolar lavage fluid (BALF) and lung homogenate were prepared for examining the ST2 protein in the lung. Lavage was performed under deep anaesthesia with a lethal dose of pentobarbital, and the trachea was cannulated with an 18gauge catheter. The lungs were inflated with $1 \mathrm{~mL}$ of cold sterile saline, the solution was slowly recovered and centrifuged at $400 \times g$ for $10 \mathrm{~min}$ at $4^{\circ} \mathrm{C}$, and the resultant supernatant was collected and analysed. $\sim 0.8 \mathrm{~mL}$ of BALF was consistently recovered, and therefore this amount was used to determine the content of ST2 protein in BALF. To obtain the lung homogenate, the remaining mice were anaesthetised, as described previously, and perfusion of pulmonary vessels with $5 \mathrm{~mL}$ saline was carried out via the right ventricle. The lungs were then excised and homogenised in $2 \mathrm{~mL}$ cold saline using a Polytron homogenizer (Kinematica) on ice. The resultant solution was centrifuged at $9,000 \times g$ for $15 \mathrm{~min}$ at $4^{\circ} \mathrm{C}$, and the supernatant was subjected to analysis. The concentrations of ST2 protein in plasma, BALF and lung homogenate were measured by ELISA.

\section{mST2 ELISA}

The mST2 ELISA system was originally constructed in our laboratory, as previously described [7]. Briefly, the bottom of a 96-well ELISA plate (Sumitomo Bakelite Co., Tokyo, Japan) was coated with rat monoclonal antibody against mouse T1/ ST2 protein (MD Biosciences, Zurich, Switzerland) and samples were added and incubated for $1 \mathrm{~h}$ at room temperature. Next, rabbit anti-mST2 polyclonal antibody [12] and HRP against rabbit IgG (GE healthcare UK Ltd, Chalfont St Giles, UK) were added consecutively. Finally, O-phenylenediamine solution was used as substrate and optical density was measured at $450 \mathrm{~nm}$ with a microplate reader (Inter Medical, Tokyo, Japan).

\section{Induction of bleomycin-induced lung injury}

Mice were anaesthetised by intraperitoneal injection of pentobarbital $\left(50 \mathrm{mg} \cdot \mathrm{kg}^{-1}\right)$, then $50 \mu \mathrm{L}$ of bleomycin (Nippon Kayaku Co., Tokyo, Japan) dissolved in sterile saline was administered intratracheally, as previously reported [15]. To determine the appropriate dosage of bleomycin, bleomycin was administered preliminarily at different doses, 2.5 and $1 \mathrm{mg} \cdot \mathrm{kg}^{-1}$ to mice. In the $2.5 \mathrm{mg} \cdot \mathrm{kg}^{-1}$-injected group, body weight decreased rapidly, and almost all animals died between days $7-10$. Conversely, in the $1 \mathrm{mg} \cdot \mathrm{kg}^{-1}$-injected group, about half of the mice remained alive. Therefore, it was established that the optimal bleomycin dose for our purpose was $1 \mathrm{mg} \cdot \mathrm{kg}^{-1}$.

In plasmid-introduced mice, at $24 \mathrm{~h}$ after gene transfer (pCAGGS and pCAGGS-mST2) to mice, blood was sampled from the tail vein and the level of ST2 protein was determined. After an additional $24 \mathrm{~h}$, as controls, the same volume of saline or the same dose of bleomycin was administered to mice after hydrodynamic injection with the same volume of saline $(6.3 \%$ of the total body weight) without plasmid vectors.

\section{Reverse transcriptase-PCR analysis}

Bleomycin-induced mRNA expression of several cytokines and mST2 was examined by reverse transcriptase (RT)-PCR analysis. Mice that had not undergone gene transfer were administered bleomycin intratracheally, and after 1,3 or 7 days, the whole lungs were removed and immediately immersed in $1 \mathrm{~mL}$ of TRI reagent (Sigma-Aldrich). After homogenisation with a Polytron homogeniser (Kinematica), total RNA was extracted and purified according to the manufacturer's protocol. Contaminated genomic DNA was destroyed by DNase I (Takara, Shiga, Japan), and cDNAs were synthesised using moloney murine leukaemia virus RT (Invitrogen, Carlsbad, CA, USA). The nucleotide sequence of the primers used were as follows. mST2: (forward) 5'- GCGGAGAATGGAACCAACTA-3', (reverse) 5'-CAATGTGTGAGGGACACTCC-3'; $\beta$-actin: (forward) $5^{\prime}$ - TGTCCCTGTATGCCTCTGGTA-3', (reverse) 5'-ACTGTGTTGGCATAGAGGTC-3'; tumour necrosis factor (TNF)- $\alpha$ : (forward) $5^{\prime}$ - CTGGGCAGGGGCCACCACGCTC-3', (reverse) 5'-CTCAGCGCTGAGTTGGTCCCCCTTCTC-3'; IL-1 $\beta$ : (forward) 5'- GCTGCTTCCAAACCTTTGAC-3', (reverse) 5'-AGGCCACAGGTATTTTGTCG-3'; and IL-33: (forward) 5'-ATGAGACCTAGAATGAAGTATTCCA-3', (reverse) 5'-TTAGATTTTCGAGAGCTTAAACATA-3'. $10 \mu \mathrm{L}$ of PCR products were developed by electrophoresis on $1 \%$ agarose gels, and the gels were stained with ethidium bromide.

\section{Measurement of cytokines and albumin in BALF}

After the treatment with bleomycin, the lungs were lavaged four times with $0.7 \mathrm{~mL}$ of cold PBS. After lavage, the total number of cells was immediately counted and the cell type was identified. For the determination of cell types, cells obtained through centrifugation in a cytospin at $120 \times g$ for 10 min were stained with Diff-Quick (Sysmax, Kobe, Japan). The remaining BALF was centrifuged at $400 \times g$ for $10 \mathrm{~min}$ at $4{ }^{\circ} \mathrm{C}$, and the supernatant was analysed. The concentrations of cytokines (TNF- $\alpha$, IL-1 $\beta$ and IL-6) in BALF were measured using ELISA kits (Biosource, Camarillo, CA, USA), and albumin concentration was measured by a turbidimetric 
immunoassay using R-ALB-UR (Kyokuto Pharmaceutical Industrial Co., Tokyo, Japan). Bronchoalveolar lavage (BAL) was performed four times with $0.7 \mathrm{~mL}$ PBS, and $\sim 2.5 \mathrm{~mL}$ was continually recovered in each case.

\section{Histology}

Mice were sacrificed and pulmonary vessels were perfused with $5 \mathrm{~mL}$ of saline via the right ventricle. Then, after intratracheal injection of $1 \mathrm{~mL}$ of $10 \%(\mathrm{v} / \mathrm{v})$ neutral formalin buffered with $0.2 \mathrm{M}$ cacodylate solution ( $\mathrm{pH} 7.4$ ), the lungs were excised and post-fixed with the same fixative for $10 \mathrm{~h}$ and were embedded in paraffin. Sections were cut into $6-\mu \mathrm{m}$ thick slices, which were stained by haematoxylin and eosin (H\&E) solution and Mallory-Azan.

To quantify the histological findings, the tissue volume density (TVD) was calculated using Scion Image software (Scion Corporation, Frederick, MD, USA), and the proportion of airspace consolidation and atelectasis to the total areas was obtained.

\section{Analysis of body weight loss and survival after bleomycin treatment}

$24 \mathrm{~h}$ after hydrodynamic gene transfer (pCAGGS and pCAGGS-mST2), bleomycin was administered intratracheally $\left(1 \mathrm{mg} \cdot \mathrm{kg}^{-1}\right)$. Over 14 days following gene transfer, the mortalities and body weights in each group of mice were monitored.

\section{Statistical analysis}

The data are presented as mean \pm SD. Statistical analyses were performed by an unpaired t-test (comparing two groups) or by ANOVA followed by the Tukey's test (comparing multiple groups), and survival analysis was performed using the Kaplan-Meier method. SPSS 11.0J (SPSS Inc., Chicago, IL, USA) was used for each statistical analysis. p-values $<0.05$ were considered statistically significant.

\section{RESULTS}

\section{Hydrodynamic gene transfer}

Hydrodynamic injection, a strategy used to transfer naked plasmid DNA into animals, was applied to obtain ST2overexpressing mice. First, in order to confirm the overexpression of the transgene by hydrodynamic injection, we injected the pGL3 control vector into the mice, and observed the luciferase expression in vivo (fig. 1a). Luciferase expression was most prominent around the upper abdomen, and was significantly elevated at day 1 . No specific signals were detected in the saline-injected mice.

Next, to confirm the transgene expression in each organ, several organs (the liver, lung, heart, kidney and spleen) were excised and the luminescence activity was measured after hydrodynamic gene transfer of the pGL3 control vector. Figure $1 \mathrm{~b}$ and $\mathrm{c}$ demonstrate that the liver showed outstanding luminescence activity, and thus, the liver is the only target organ of this gene transfer method. The other organs from the pGL3-injected mice showed lower luminescence activity than the liver, but higher activity than that of control mice. Furthermore, to detect transgene expression visually, pCAGGS-LacZ was administered in the same manner, and the liver and lung were excised and stained with X-gal solution. As shown in figure 1d, the liver was clearly stained blue; however, there was almost no detectable $\beta$-galactosidase expression in the lung (fig. 1e). This outcome corresponded to the results of the bioluminescent assay.

\section{Transient overexpression of $\mathbf{m S T 2}$ protein}

Before in vivo application, to confirm the production of mature mST2 protein from the constructed plasmid, pCAGGS and pCAGGS-mST2 were transferred into HEK 293T cells. The culture supernatant was collected for Western blotting. As shown in figure $2 \mathrm{a}$, both the glycosylated mature form of ST2 $(60-70 \mathrm{kDa})$ and the core peptide $(37 \mathrm{kDa})$ obtained by digestion with $\mathrm{N}$-glycosidase F were clearly detected. The results indicated that the mature ST2 protein was appropriately expressed and secreted from the cultured cells using our constructed plasmid.

We then carried out in vivo gene transfer into mice using hydrodynamic injection. First, we determined the appropriate amount of plasmid for obtaining the maximum plasma concentration of the ST2 protein. As shown in figure $2 b$, various amounts of plasmid vectors $(10-100 \mu \mathrm{g})$ were introduced, and the concentration of plasma ST2 protein increased significantly in accordance with the amount of plasmid administered. It reached a maximum level when $50 \mu \mathrm{g}$ of the plasmid was injected, but no significant increase was observed when the amount of plasmid was increased from 50 to $100 \mu \mathrm{g}$. Therefore, the amount of the plasmid was fixed at $50 \mu \mathrm{g}$ for the subsequent in vivo experiments.

The time-kinetics of the introduced ST2 protein were examined next. As shown in figure 2c, the ST2 protein level in plasma attained a peak at $\sim 12-24 \mathrm{~h}\left(18.1-27.6 \mu \mathrm{g} \cdot \mathrm{mL}^{-1}\right)$ and gradually decreased until 21 days $\left(4.07 \mu \mathrm{g} \cdot \mathrm{mL}^{-1}\right)$. Empty vector-injected mice showed no increase in ST2 level from the beginning to the end of the trial, indicating that the injection of plasmids itself did not exert any influence on the endogenous ST2 level. For examination of the level of local ST2 protein in the lung, $1 \mathrm{~mL}$ of saline was injected intratracheally to obtain BALF, and almost constant recovery of $0.8 \mathrm{~mL}$ was obtained. The level of BALF ST2 protein was $10.81 \pm 3.31 \mathrm{ng} \cdot \mathrm{mL}^{-1}$, as measured by ELISA, and therefore the BALF ST2 protein content was estimated at $8.65 \pm 2.65 \mathrm{ng} \cdot \mathrm{BALF}^{-1}$. To collect lung homogenate, the lungs were excised and homogenised in $2 \mathrm{~mL}$ of saline. Since the concentration of ST2 protein was $23.57 \pm 12.72 \mathrm{ng} \cdot \mathrm{mL}^{-1}$, the content of ST2 protein in lung homogenate was $47.14 \pm 25.43 \mathrm{ng}$ (fig. $2 \mathrm{~d}$ and e).

Since the hydrodynamic method has been known to cause liver damage, AST and ALT levels were monitored after the injection. In the current study, AST/ALT levels were elevated at day 1 , but returned to the normal range by day 2 . There were no significant time-course differences in the serum AST/ALT concentration between empty vector-introduced mice and ST2overexpressing mice (fig. $2 \mathrm{f}$ and $\mathrm{g}$ ).

\section{mRNA expression of pro-inflammatory cytokines, endogenous ST2 and IL-33 in bleomycin-induced lung injury}

TNF- $\alpha$ and IL-1 $\beta$ are pro-inflammatory cytokines that have been reported to be upregulated immediately after bleomycin exposure, and to play principal roles in the exacerbation of 
a)

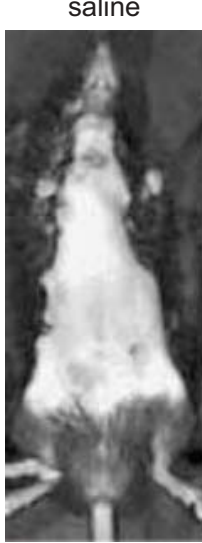

Day 1
pGL3

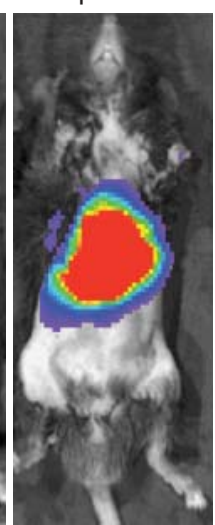

Day 1
pGL3

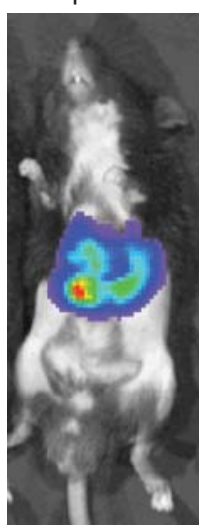

Day 2
pGL3

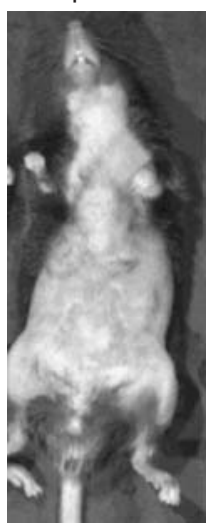

Day 7

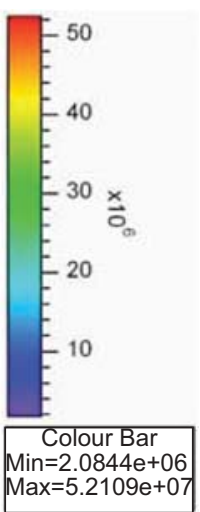

$\operatorname{Max}=5.2109 \mathrm{e}+07$
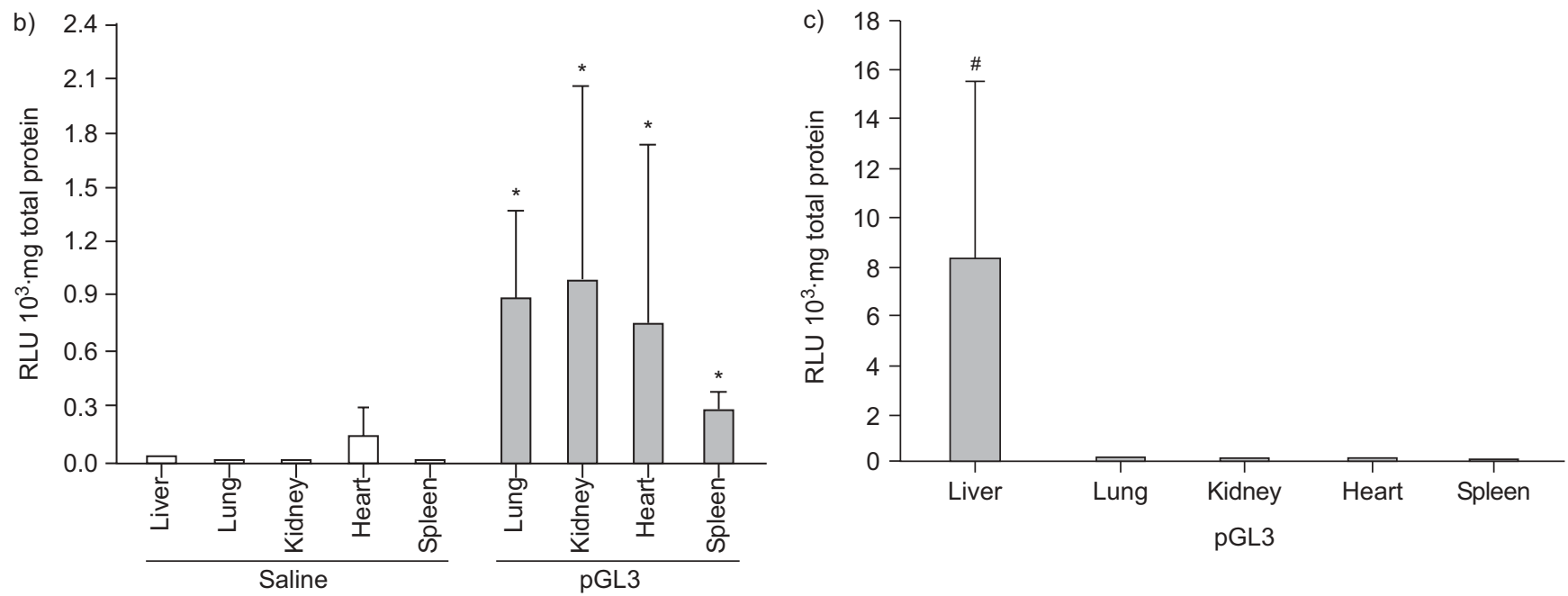

d)

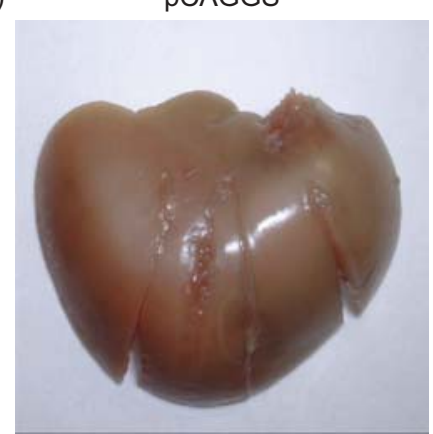

pCAGGS-LacZ

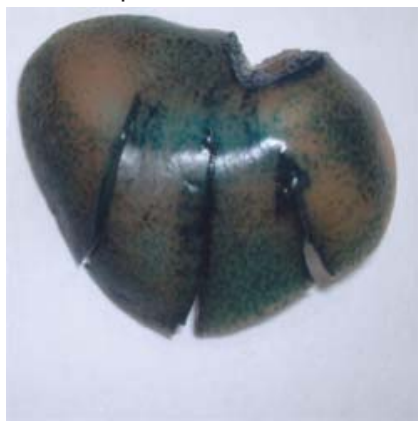

e)

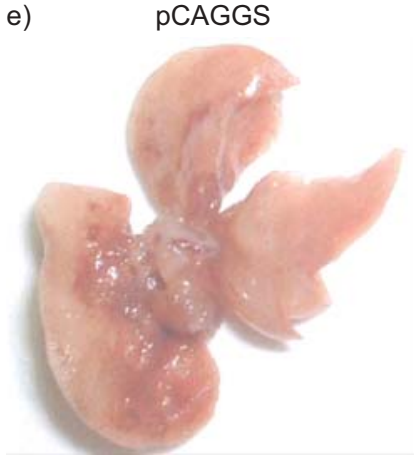

pCAGGS-LacZ

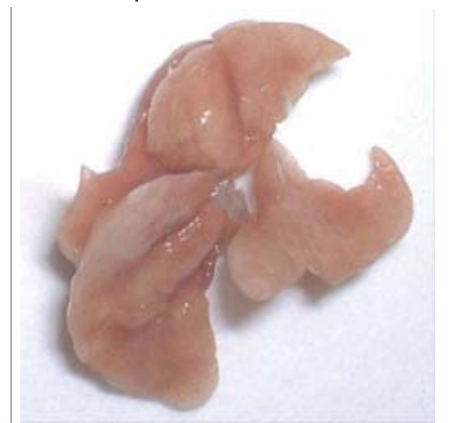

FIGURE 1. Detection of gene expression transferred by hydrodynamic injection. a) In vivo imaging of mice after the hydrodynamic injection of saline and pGL3 control vector. Luciferase expression was detected from the ventral surface of the body by IVIS (Xenogen, Alameda, CA, USA) for up to 7 days. The right panel indicates photon intensity correlating with the gene expression. The data are representative of four separate experiments showing similar results. b and c) Ex vivo luciferase assay of the individual organs. The luciferase activities of the liver, lung, heart, kidney and spleen at $24 \mathrm{~h}$ after the hydrodynamic injection of saline (control; $\square$ ) and pGL3 control vector $(\square)$ were demonstrated as the relative light units (RLU) per total protein content. c) The luciferase activity of the liver was demonstrated independently using another scale. Data are presented as mean $\pm S D, n=4$, and are representative of two independent experiments. ${ }^{*}: p<0.05 ;{ }^{*}: p<0.01$ versus relevant organ of saline injected group; $\#$ : $p<0.01$ versus other organs of pGL3-injected mice. General view of the left lobe of the liver (d), and right lobe of the lung (e) at $48 \mathrm{~h}$ after the hydrodynamic injection of PCAGGS or pCAGGS-LacZ. Each organ was excised and stained with 5-bromo-4-chloro-3-indolyl- $\beta$-D-galactopyranoside solution. Blue staining indicates the expression of $\beta$-galactosidase.

lung injury [16, 17]. In the present study, therefore, we examined the lung mRNA expression of the pro-inflammatory cytokines TNF- $\alpha$ and IL-1 $\beta$ after the intratracheal injection of bleomycin. As shown in figure 3, bleomycin treatment remarkably increased the mRNA levels of TNF- $\alpha$ and IL-1 $\beta$ at day 1 , demonstrating that acute lung injury occurred. The levels of both cytokines were decreased from day 3-7. We also examined the levels of lung endogenous ST2 and IL-33 mRNA, 
a)
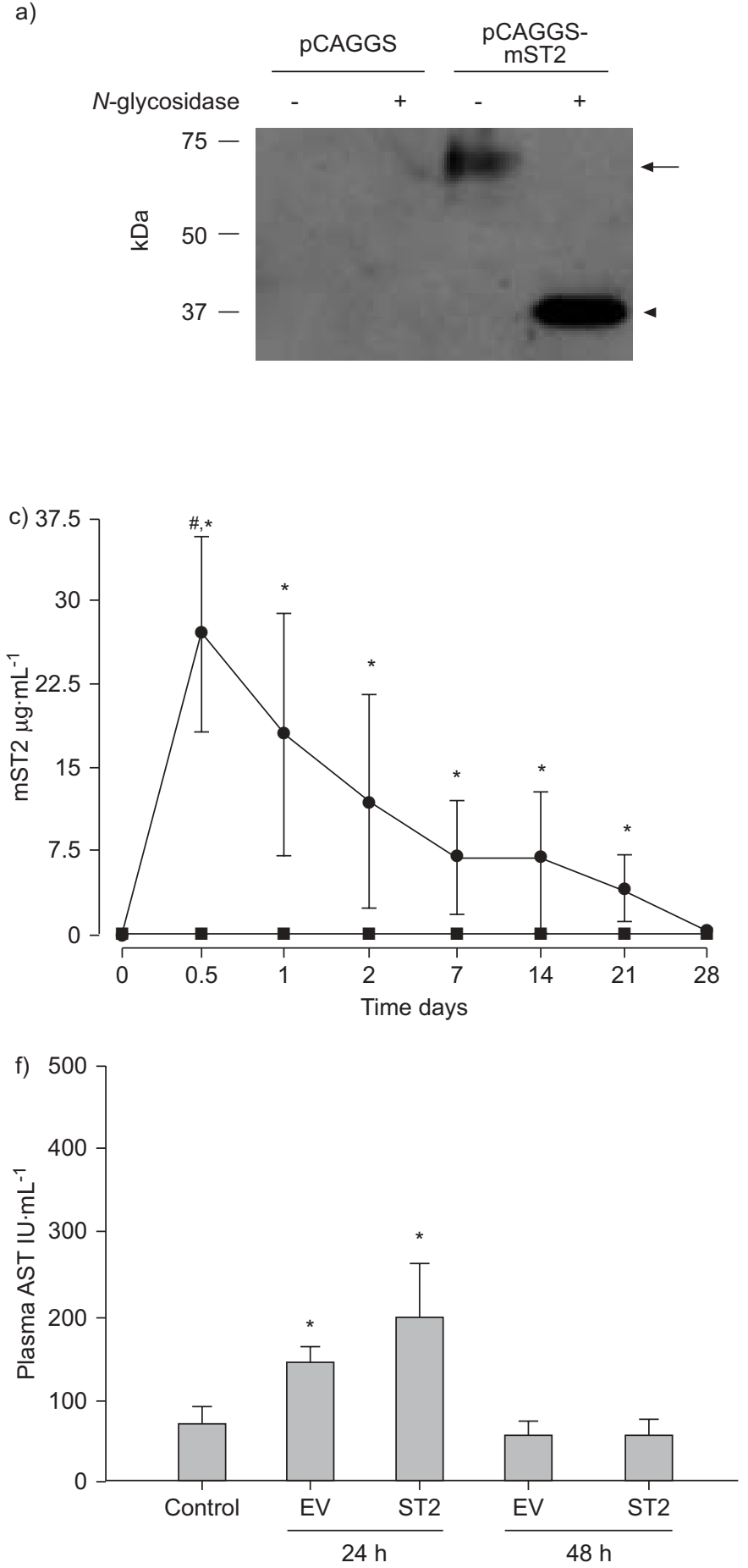
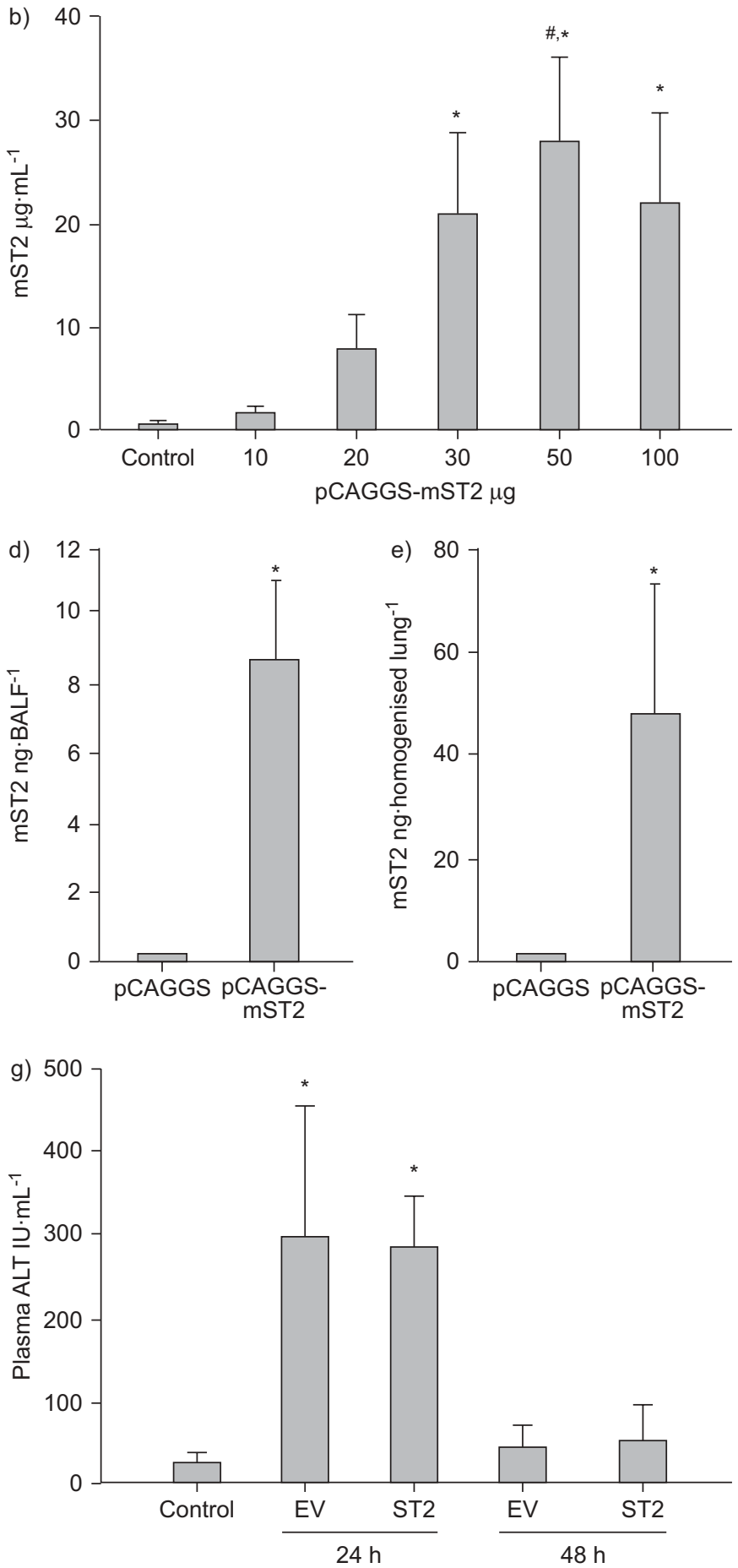

FIGURE 2. Assessment of ST2 gene transfer in vitro and in vivo. a) In vitro detection of mouse ST2 protein in the supernatants of human embryonic kidney (HEK) $293 \mathrm{~T}$ cells after the gene transfer of pCAGGS and pCAGGS-mST2. These plasmid vectors were transferred by the calcium-phosphate method, and $24 \mathrm{~h}$ later, supernatants were collected and subjected to Western blotting. The presence of mature glycosylated ST2 protein (60-70 kDa; arrow) and deglycosylated core peptide (37 kDa; arrowhead) was confirmed. b) Concentration of plasma ST2 protein in mice injected with various amounts of plasmids. Mice were sacrificed at $12 \mathrm{~h}$ after the hydrodynamic injection of plasmid (pCAGGS-mST2) or same volume of saline (control), and the plasma was collected to measure the ST2 concentration. The data are presented as mean \pm SD, $n=4$, and are representative of three independent experiments. *: $p<0.05$ compared with saline-injected mice; ${ }^{*}: p<0.05$ compared with other plasmid doses. c) Time kinetics of plasma ST2 protein after the hydrodynamic injection with $50 \mu \mathrm{g}$ of plasmid. Mice were bled consecutively from the tail vein on each day, and plasma was prepared. The data are presented as the mean $\pm S D, n=4$, and are representative of three independent experiments. *: $p<0.05$ pCAGGS-injected group versus pCAGGS-mST2-injected group at the same plasmid dose; ${ }^{*}:$ p $<0.05$ compared with other timing in pCAGGS-mST2-injected group. • : pCAGGS-mST2; $\mathbf{a}$ : pCAGGS. d and e) ST2 protein in lung homogenate (d) and bronchoalveolar fluid (BALF; e) at $24 \mathrm{~h}$ after hydrodynamic injection. The data are presented as mean $\pm \mathrm{SD}, \mathrm{n}=3,{ }^{*}: \mathrm{p}<0.05 \mathrm{compared}$ with $\mathrm{pCAGGS}$ injected mice. $f$ and g) Serum aspartate aminotransferase (AST; f) and alanine aminotransferase (ALT; g) levels after the hydrodynamic gene transfer. The data are presented as the mean $\pm S D, n=3$, and are representative of two independent experiments. ${ }^{*}: \mathrm{p}<0.05$ compared with saline injected mice (without plasmid injection). EV: empty vector. 
which were weakly and constitutively expressed without bleomycin treatment; however, these mRNAs gradually increased in a time-dependent manner from day 3 to day 7 after bleomycin treatment.

\section{Analysis of BALF cell counts and cell types after bleomycin administration}

To examine the acute extravasation of inflammatory cells into the pulmonary interstitium caused by bleomycin, BAL was performed at day 1 and day 3 after bleomycin treatment, and we analysed the total cell counts and cell types. Compared with the levels in control mice treated with saline, the total cell numbers and number of neutrophils were significantly elevated at day 1 in bleomycin-treated mice (fig. $4 a$ and b).

We then examined whether the ST2 protein affected the initial inflammatory phase in acute lung injury, using bleomycintreated ST2-overexpressing mice and mice injected with empty vector as controls. The time course is presented in figure 5 . First, it was confirmed that the hydrodynamic injection itself did not affect the total cell count in the empty vector- and pCAGGS-ST2-injected mice (fig. 4a). In mice treated with empty vector plus bleomycin and mice treated with bleomycin alone, the total number of cells immediately increased on day 1. However, in ST2-overexpressing mice, the total cell number was significantly reduced compared with the other bleomycintreated mice. Furthermore, in mice with empty vector plus bleomycin, numbers of neutrophils were prominently elevated at day 1. In contrast, a significant decrease in the number of neutrophils and lymphocytes was evident on day 1 in ST2overexpressing mice (fig. $4 \mathrm{~b}$ ).

Conversely, on day 3 , the total cell counts in ST2-overexpressing mice were estimated to be almost equivalent to those in mice treated with bleomycin alone, as well as empty vector-injected plus bleomycin-treated mice. However, even though there were no significant statistical differences, the counts of neutrophils were relatively low and the counts of

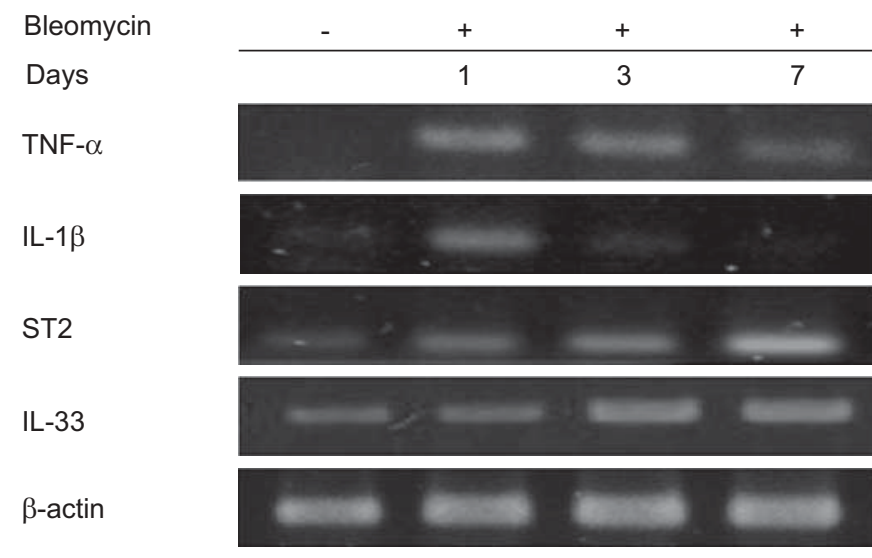

FIGURE 3. mRNA expression of pro-inflammatory cytokines, ST2 and interleukin (IL)-33 after bleomycin treatment. Bleomycin was administered intratracheally to wild-type mice at days 1, 3 and 7, after day 7 the whole lung was excised and each mRNA expression was assayed. Mice without bleomycin treatment were controls. $\beta$-actin was a house-keeping gene and provided endogenous control. Similar results were obtained in three separate experiments. TNF- $\alpha$ : tumour necrosis factor- $\alpha$. lymphocytes were high in ST2-overexpressing mice, compared with the other bleomycin-treated groups.

\section{Pro-inflammatory cytokines and albumin levels in BALF}

In the present study, total cell counts and neutrophils were particularly increased in the initial phase of bleomycininduced lung injury. The concentrations of pro-inflammatory cytokines in BALF at day 1 after the bleomycin treatment were then assayed and compared between groups. In bleomycintreated mice, significant increases of TNF- $\alpha$, IL-1 $\beta$ (data not shown) and IL-6 were demonstrated, and levels were almost equivalent to or slightly lower than those in the mice treated with empty vector plus bleomycin. In ST2-overexpressing mice, the concentration of TNF- $\alpha$ was significantly reduced compared with that of mice injected with empty vector plus bleomycin or that of mice treated with bleomycin alone (fig. 6a). In addition, the level of IL-6 was also significantly decreased in ST2-overexpressing mice (fig. 6b). The level of IL$1 \beta$ was slightly lower in ST2-overexpressing mice, but there were no statistically significant differences (data not shown).

The albumin concentration in BALF is frequently used as an indicator of pulmonary vascular permeability, especially in the case of acute lung injury. In fact, bleomycin treatment induced a significant increase in albumin levels in bleomycin-treated mice in the present study. However, in ST2-overexpressing mice, the albumin concentration was significantly lower than in other bleomycin-treated mice (fig. 6c).

\section{Histological examination of the effect of ST2 protein on bleomycin-induced lung injury}

The effect of the ST2 protein on acute phases of bleomycininduced lung injury was investigated histologically (fig. 7a and b). Mice treated only with saline exhibited a small-scale interstitial oedema in the early phase (day 1), but no inflammatory cells were observed in the perivascular area at that time (fig. 7a). The impact of the hydrodynamic injection histologically was also examined; the plasmid injection itself did not affect the pulmonary architecture (fig. 7a). Conversely, both the mice treated with bleomycin alone and those treated with empty vector plus bleomycin showed an accumulation of inflammatory cells around the bronchovascular bundle, and in higher magnification, many neutrophils with segmented nuclei and some round mononuclear cells were recognised (fig. $7 \mathrm{~b}$ ). In contrast, rare inflammatory cells were observed in the peribronchial area in ST2-overexpressing mice, but accumulations of neutrophils were not observed (fig. 7a and b).

In general, following the inflammatory phase in bleomycininduced lung injury, connective tissues and extracellular matrix are increased [17]. We performed Mallory-Azan and H\&E staining of the lung tissue sections on day 7 after administration of bleomycin (fig. 8). Mice treated with saline alone and mice injected with plasmid vector alone had no inflammatory change and no alteration of the pulmonary architecture was observed (fig. 8a). However, a large number of inflammatory cells was observed in the mice treated with bleomycin alone and those treated with empty vector plus bleomycin; the infiltrating cells accumulated in the subpleural and peribronchial areas, and the airspaces showed wide-ranging collapse (fig 8a). Furthermore, there was a large amount of blue-stained connective tissue throughout the alveolar interstitium, especially in the severely 
$$
\text { a) }
$$

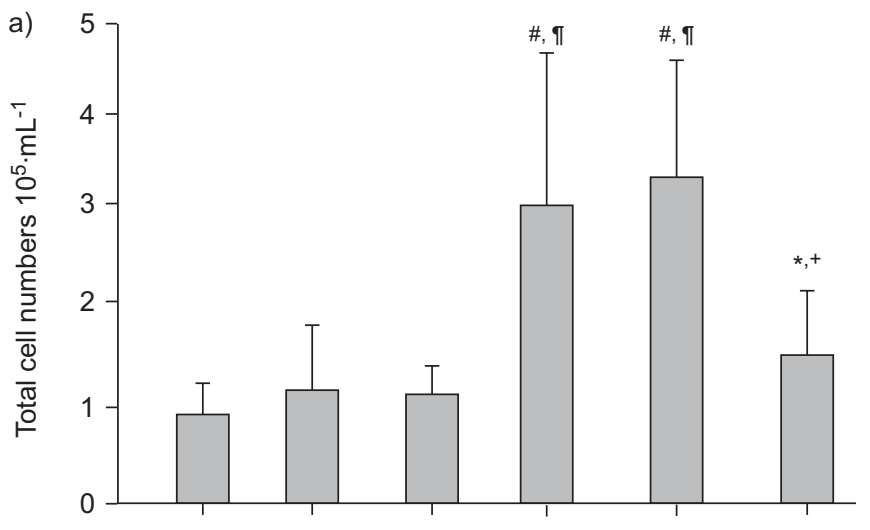

\begin{abstract}
Bleomycin saline
\end{abstract}
$\begin{array}{llllll}\text { Plasmid } \quad- & \text { EV } & \text { ST2 } & - & \text { EV } & \text { ST2 }\end{array}$

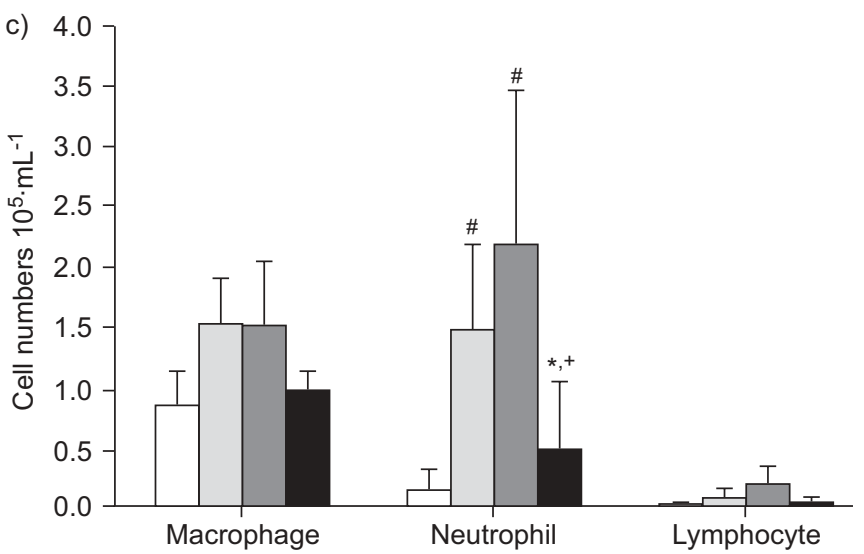

b)

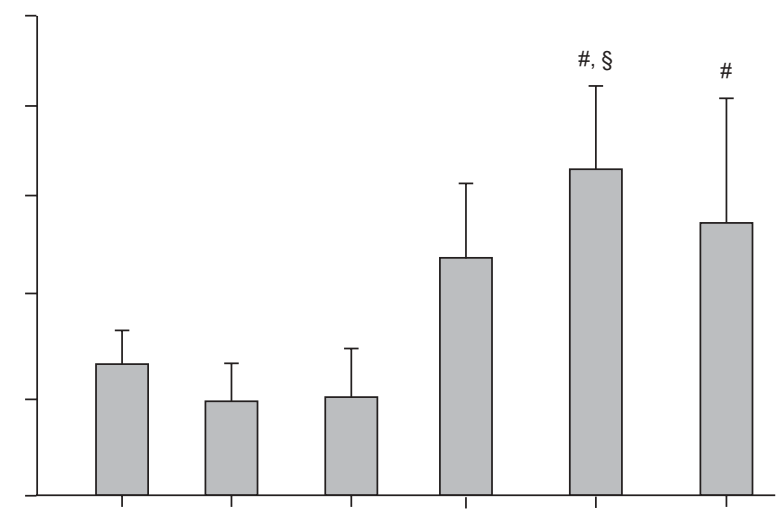

Bleomycin saline

d)

FIGURE 4. Analysis of total cell numbers and cell types in bronchoalveolar lavage fluid (BALF). BALF analysis was performed in mice with or without hydrodynamic gene transfer at day 1 ( $a$ and $c$ ) and day 3 ( $b$ and d) after the administration of bleomycin. a and b) Total cell numbers and $c$ and d) cell types in BALF are shown. The data are presented as the mean \pm SD of four independent experiments. $a$ and $b$ ) Saline: $n=5$; bleomycin: $n=6$; EV (empty vector; pCAGGS) or ST2 (pCAGGS-mST2): $n=3$; and EV or ST2 +bleomycin: $n=10$. $c$ and d) Saline $(\square)$ : $n=5$; bleomycin $(\square): n=6$; and EV ( $\square)$ or ST2+bleomycin $(\mathbf{\square}): n=8$. *: $p<0.05$ ST2 plus bleomycin versus bleomycin alone; ${ }^{+}: p<0.01$ ST2 plus bleomycin versus EV plus bleomycin; * : $p<0.01$ compared with saline; ${ }^{\text {: }} p<0.01$ compared with EV and ST2 (without bleomycin); ${ }^{\text {s: }} p<0.05$ compared with bleomycin alone.

damaged area (fig. 8b). Conversely, in ST2-overexpressing mice, some inflammatory cells were observed, but the areas of inflammation were restricted. Most of the alveolar structure looked nearly normal, and it was clear that there was less connective tissue compared with other bleomycin-treated mice (fig. $8 \mathrm{a}$ and b).

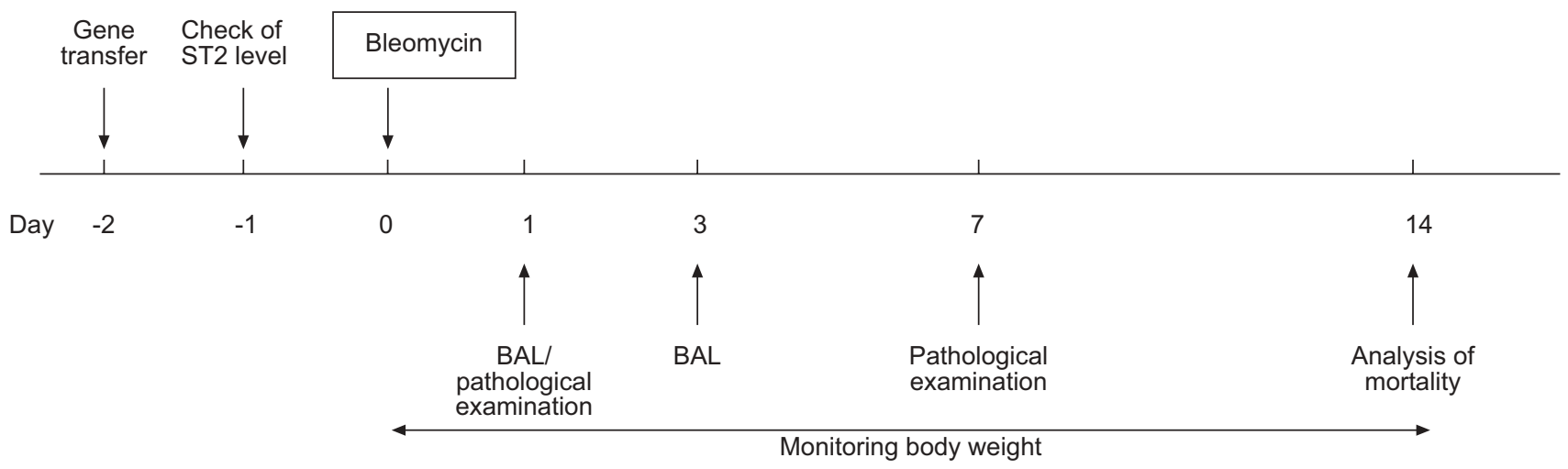

FIGURE 5. Time course of the experiments. The time course of the experiments to examine the effect of ST2 for the bleomycin-induced acute lung injury was presented schematically. The gene transfer was performed by the hydrodynamic injection of plasmids. BAL: bronchoalveolar lavage. 


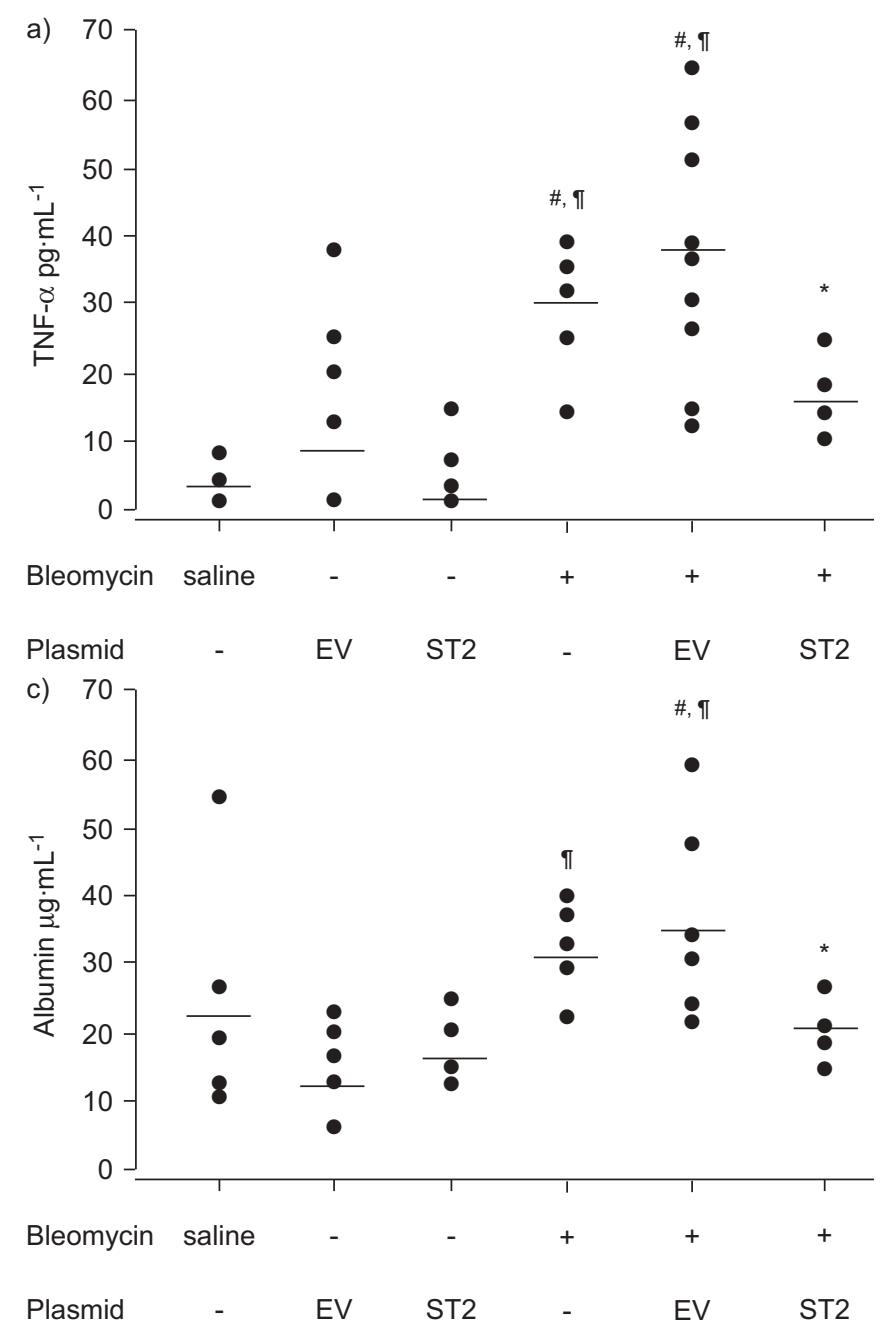

Next, Scion Image software was used (Scion Corporation, Frederick, MD, USA) to quantify TVD to visualise the histological results at day 7 after bleomycin treatment. TVD was presented as the ratio of the collapsed high-density area to total area, and it increased in proportion to the extent of lung injury. Mice treated with bleomycin alone or treated with empty vector plus bleomycin showed significantly higher TVD than saline-treated mice. Conversely, in ST2-overexpressing mice treated with bleomycin, TVD was significantly lower than in other bleomycin-treated mice (fig. 8c).

\section{Body weight loss and survival rate in bleomycin-induced lung injury}

Body weight loss was monitored during the 14 days after bleomycin administration in ST2-overexpressing mice and empty vector-injected mice (fig. 9a). During the first week, most of the experimental mice remained alive, but their body weights decreased to varying degrees. In the second week, although the difference between the two groups was not statistically significant, the empty vector-injected mice continuously lost body weight, while the body weight of the ST2overexpressing mice tended to remain constant.

Finally, we compared the survival rate for 14 days after bleomycin administration between ST2-overexpressing mice

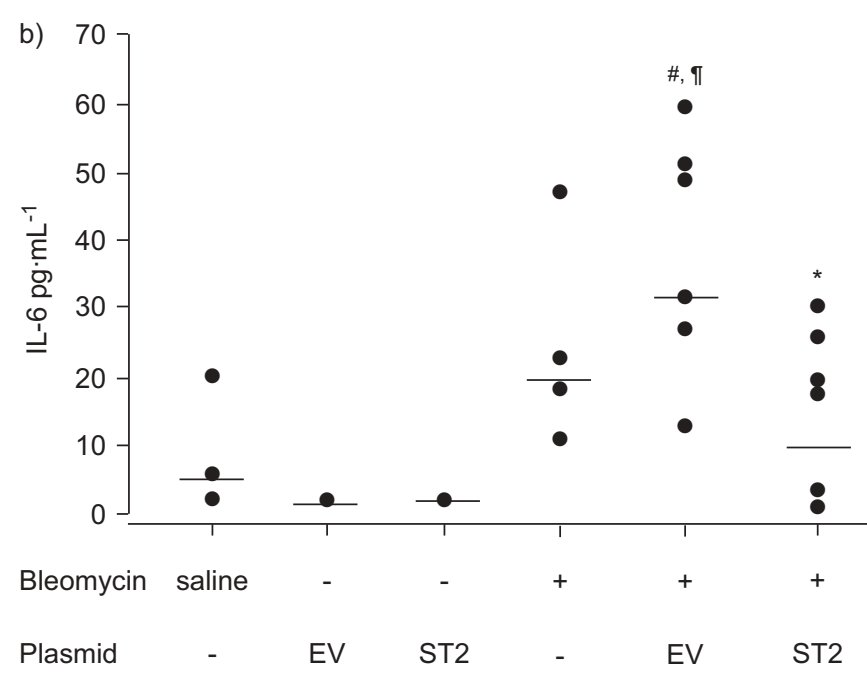

FIGURE 6. Pro-inflammatory cytokines and albumin concentration in bronchoalveolar lavage fluid (BALF). The concentrations of a) tumour necrosis factor (TNF)- $\alpha$, b) interleukin (IL)-6 and c) albumin were analysed at day 1 after treatment with bleomycin or saline. Cytokines were measured by ELISA. The albumin concentration was measured by a turbidimetric immunoassay. Data are representative of two independent experiments. Saline: $n=5$, bleomycin alone: $n=6$; and empty vector (EV) (pCAGGS) or ST2 (pCAGGS-mST2) plus bleomycin: $n=8$. * $p<0.05$ ST2 plus bleomycin versus EV plus bleomycin; ${ }^{\#}: p<0.01$ compared with saline; ": $p<0.01$ compared with EV and ST2 (without bleomycin). _— : average.

and the other groups of mice (saline, bleomycin and empty vector plus bleomycin; fig. 9b). The survival rate of ST2overexpressing mice was $84.0 \%$ at day 14 and the mean survival time was 13.44 days (95\% confidence interval (CI) 12.92-13.96). The survival rates of mice treated with an empty vector plus bleomycin and bleomycin treatment alone were $43.5 \%$ and $63.6 \%$ and mean survival times were 11.7 (95\% CI $10.58-12.81)$ and 12.2 days and (95\% CI 10.76-13.60), respectively. ST2-overexpressing mice showed significantly higher survival rates than the other control groups. No mice died from hydrodynamic injection only (data not shown).

\section{DISCUSSION}

Some recent reports have suggested that the ST2 protein is induced by various inflammatory stimuli and may play an anti-inflammatory role in vivo [6-10]. TAJIMA and co-workers $[8,18]$ reported an increase of serum ST2 protein in acute exacerbation of idiopathic pulmonary fibrosis, and that ST2 gene expression was induced in the murine lung by intratracheal administration of bleomycin. Therefore, we speculated that ST2 was closely related to lung inflammation. We induced acute lung injury using bleomycin in the present study, and then assessed the effect of ST2 protein in vivo. 
a)

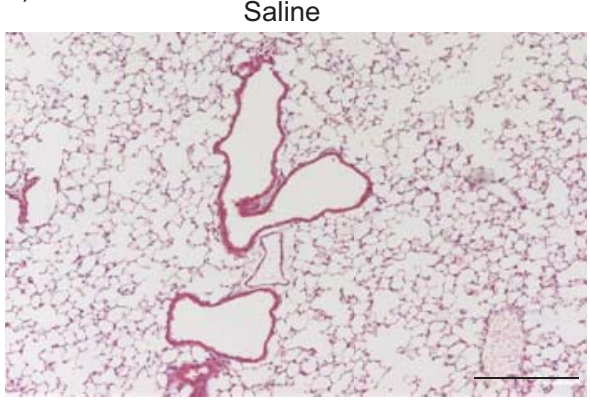

\section{Bleomycin}

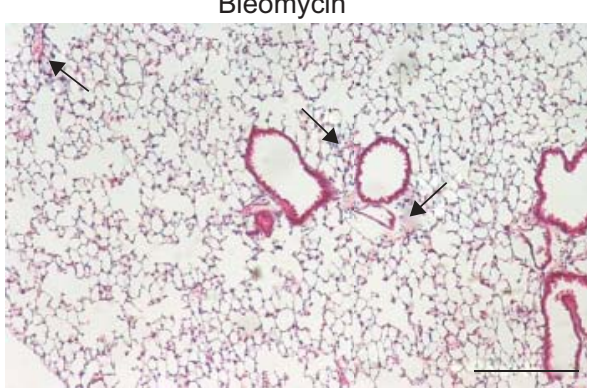

EV

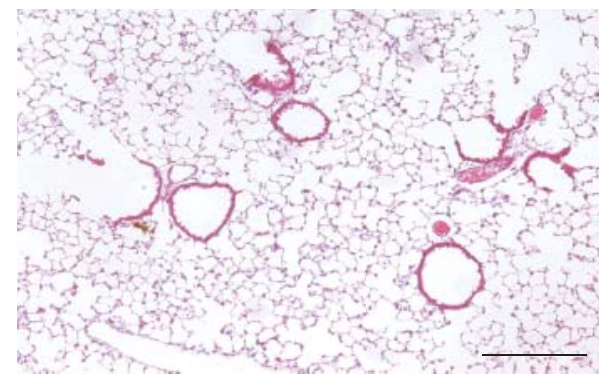

$\mathrm{EV}+$ bleomycin

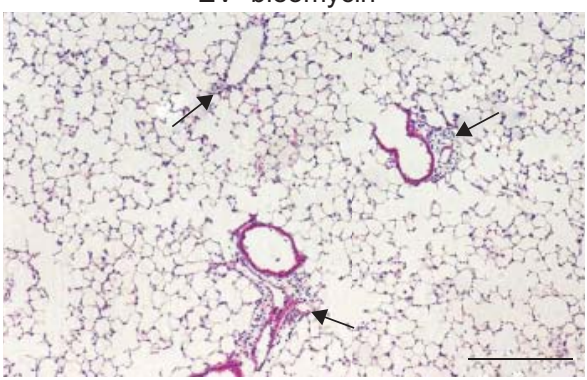

ST2

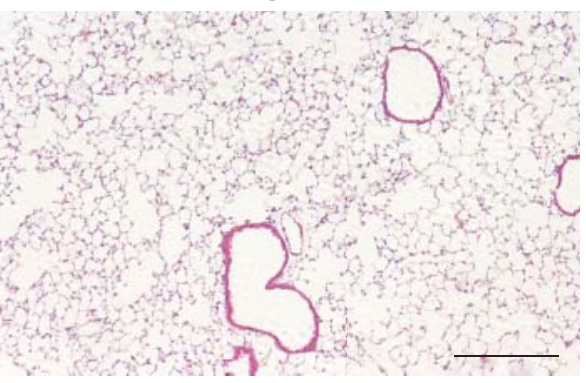

ST2+bleomycin

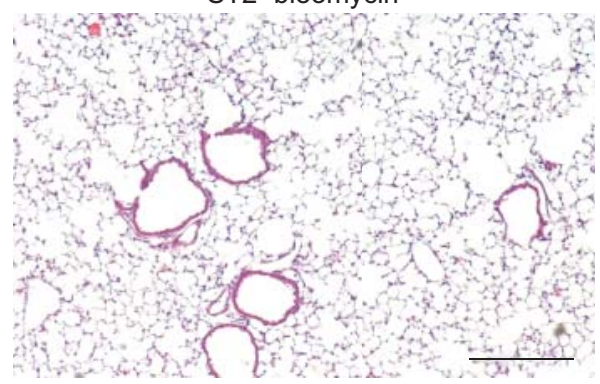

b)
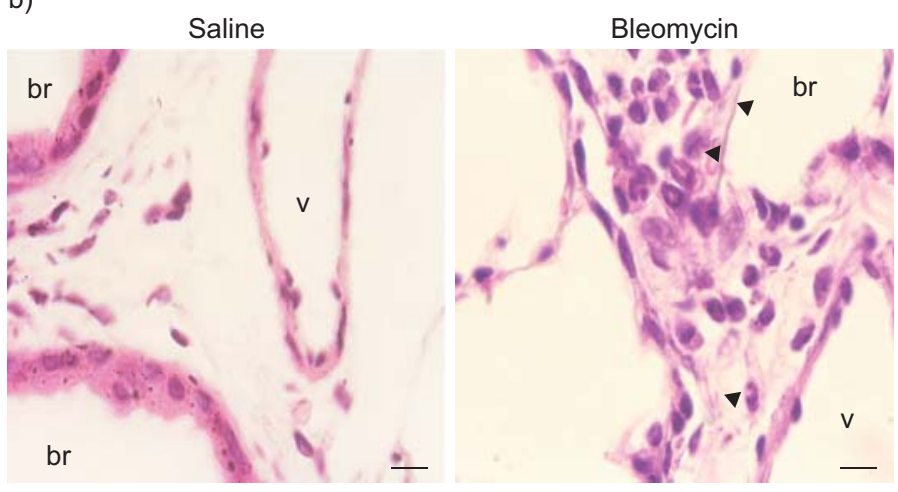

$\mathrm{EV}+$ bleomycin
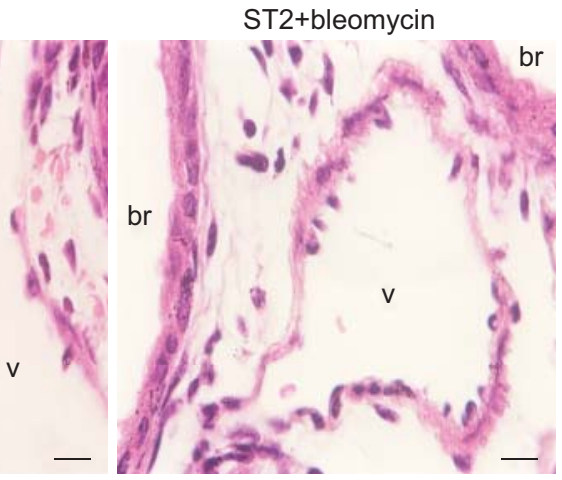

FIGURE 7. Histological findings at day 1 after treatment with bleomycin. Photomicrographs of lung sections from mice treated with saline, empty vector (EV; pCAGGS) alone, ST2 (pCAGGS-mST2) alone, bleomycin alone, EV plus bleomycin and ST2 plus bleomycin at day 1 after treatment. a) Lower magnification (Scale bars=200 $\mu \mathrm{m})$ and b) focused on bronchovascular bundles at a higher magnification (Scale bars $=10 \mu \mathrm{m}$ ) of mice treated with saline, bleomycin alone, EV plus bleomycin and ST2 plus bleomycin. Sections were stained with haematoxylin and eosin. Arrows: accumulation of inflammatory cells; arrowheads: neutrophils. br: bronchiole; v: vessel.

In order to examine the effect of the ST2 protein in mice, we first purified and administered recombinant ST2 protein to mice. However, unlike in vitro studies, an enormous amount of ST2 protein was needed in order to attain the high ST2 level in vivo. Then, a hydrodynamic injection method was employed, which is an efficient method for transient gene transfer to adult animals [13, 14, 19], and high levels of target gene expression can be achieved by the rapid injection of naked plasmid in a large volume. Corroborating previous reports [19], we confirmed that the main transgene-expressing organ was the liver; however, the ST2 protein was released into the systemic circulation and attained a high level $12 \mathrm{~h}$ after the gene transfer. The transgene expression level depends on the injection speed, injection volume, target organ and the choice of promoter of the plasmid vectors. We used the pCAGGS vector, which was driven by the chicken $\beta$-actin promoter that enabled us to maintain a high level of expression in mammalian cells. However, the appropriate plasma ST2 level to achieve an anti-inflammatory effect for mice treated with bleomycin has not been established in vivo. According to a previous report, $100 \mu \mathrm{g}$ of ST2 protein is required to prevent endotoxin shock in mice [9]. Therefore, in the present study, we used a high dose of plasmid $\left(50 \mu \mathrm{g} \cdot\right.$ mouse $\left.^{-1}\right)$ to obtain the maximal plasma concentration of ST2 $\left(18.1-27.6 \mu \mathrm{g} \cdot \mathrm{mL}^{-1}\right)$.

In the present report, we demonstrated that the ST2 protein hindered the invasion of neutrophils and the subsequent capillary leakage in acute lung injury for the first time. In addition, TNF- $\alpha$, IL- $1 \beta$ and IL- 6 are known to play pivotal roles in the induction of lung inflammation, leukocyte migration, and the production of other cytokines and chemokines [20,21], and these cytokines were elevated in BALF in bleomycininduced acute lung injury. However, we found that the levels of TNF- $\alpha$ and IL-6 in BALF were significantly decreased in ST2-overexpressing mice at day 1 after bleomycin treatment. In previous in vitro experiments, it was demonstrated that ST2 inhibited the production of pro-inflammatory cytokines in macrophages derived from bone marrow $[9,11]$, as well as in a 
a)

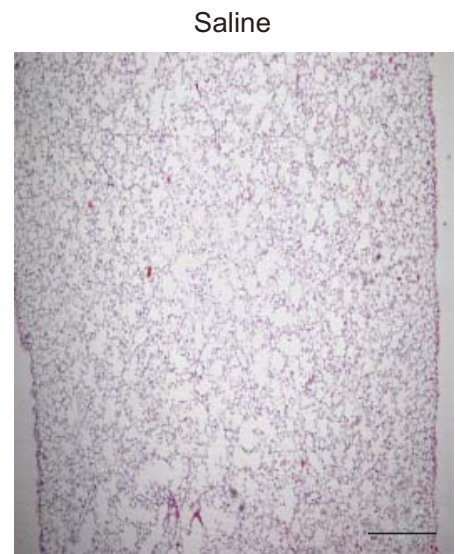

Bleomycin

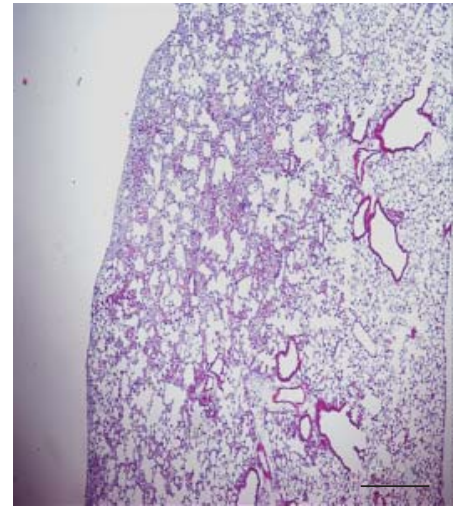

EV

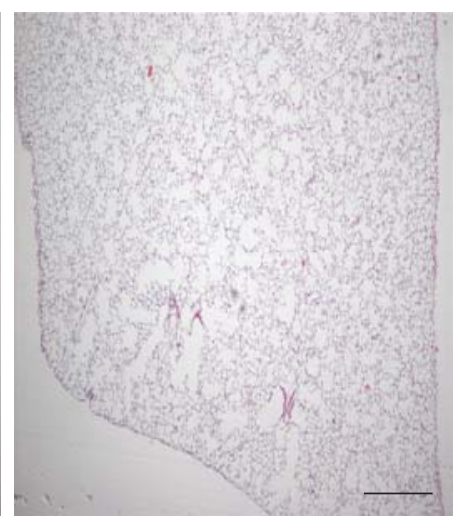

EV+bleomycin

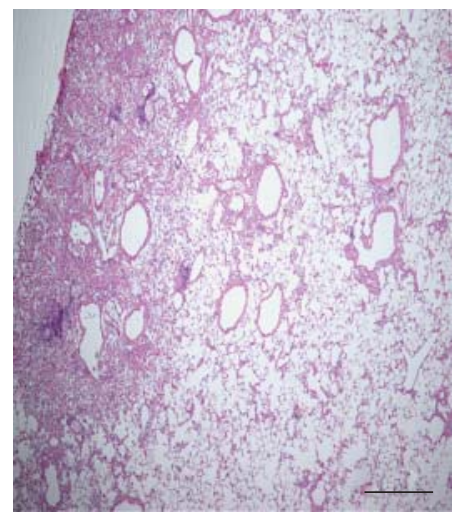

ST2

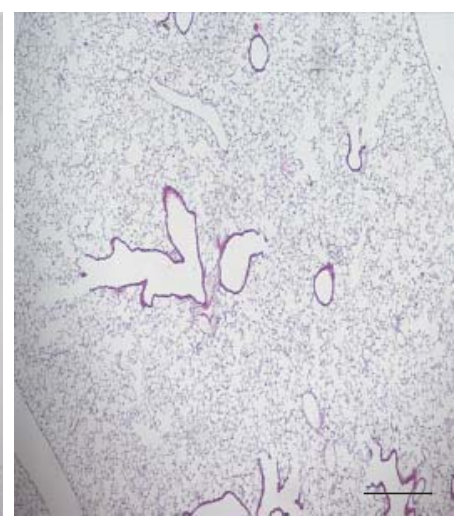

ST2+bleomycin

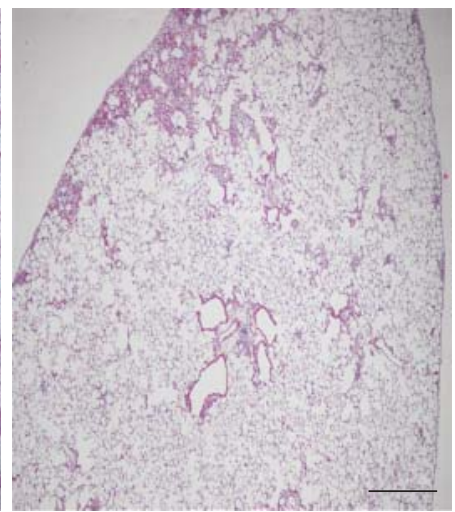

b)

Saline
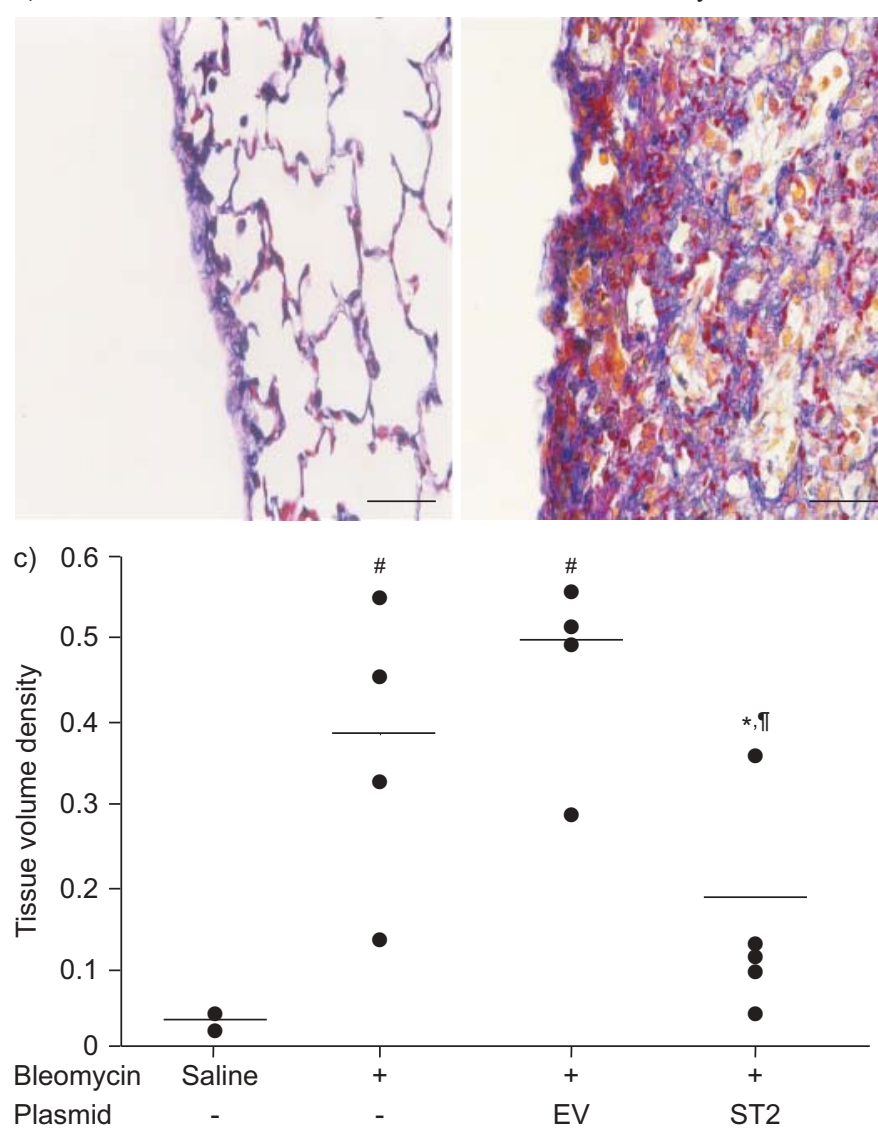

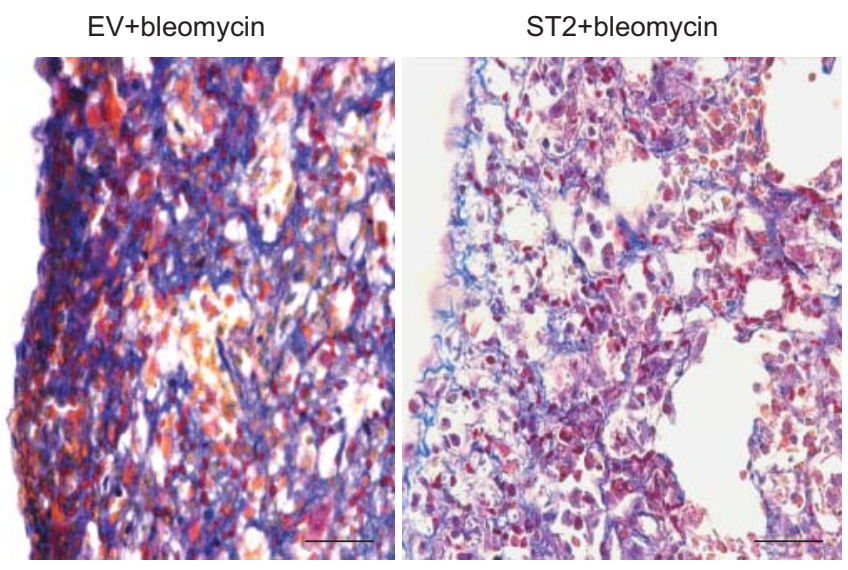

FIGURE 8. Histological findings at day 7 after treatment with bleomycin Photomicrographs of lung sections from mice treated with saline, empty vector (EV; pCAGGS) alone, ST2 (pCAGGS-mST2) alone, bleomycin alone, EV plus bleomycin and ST2 plus bleomycin. a) Stained with haematoxylin and eosin (Scale bars $=640 \mu \mathrm{m}$ ) and b) stained with the Mallory-Azan method (Scale bars $=50 \mu \mathrm{m}$ ). c) Tissue volume density is demonstrated as the proportion of air space consolidation per total volume. Saline: $\mathrm{n}=3$ and bleomycin; EV plus bleomycin and ST2 plus bleomycin: $n=4$; and data are representative of three independent experiments. *: $p<0.05$ bleomycin alone versus ST2 plus bleomycin; " $p<0.01 \mathrm{EV}$ plus bleomycin versus ST2 plus bleomycin; \#: p<0.01 compared with saline. 

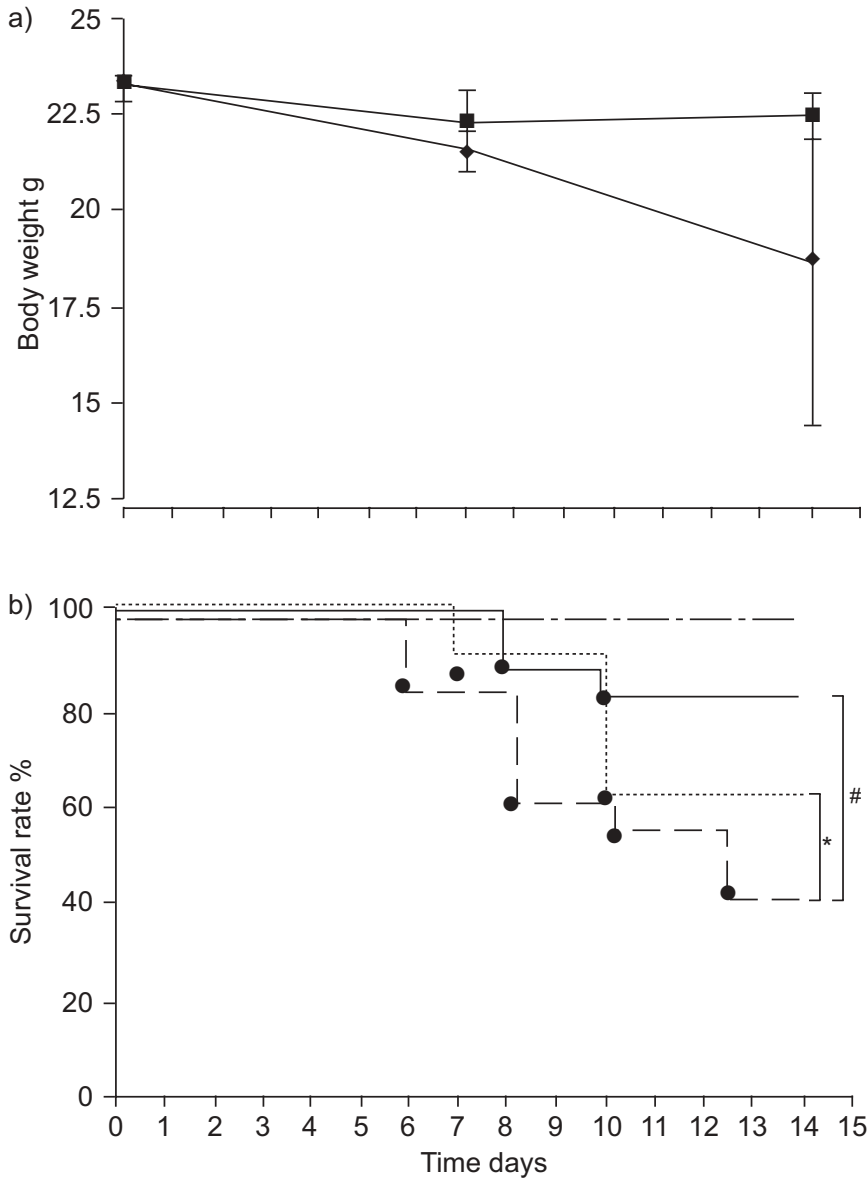

FIGURE 9. Body weight loss and survival rate of mice with bleomycin-induced lung injury. a) Comparison of body weight loss in mice treated with empty vector (EV) plus bleomycin ( ) and ST2 (pCAGGS-mST2) plus bleomycin ( $\mathbf{\square}$ ) between day $0-14$ ( $n=8$ in both groups); $p=0.08$. b) The survival rate of mice was monitored for 14 days and analysed using the Kaplan-Meier method. Mice that died through injurious tracheotomy or deep anaesthesia were excluded. Saline $(-\cdot-\cdot-)$ : $n=7$; bleomycin alone ( . . .): $\mathrm{n}=14$; and EV plus bleomycin (- - - ) or ST2 plus bleomycin (-): $n=23$. *: $p<0.05$ bleomycin alone versus ST2 plus bleomycin; \#: $p<0.01 \mathrm{EV}$ plus bleomycin versus ST2 plus bleomycin (see online supplementary material). Serum ST2 level after the injection of lipopolysaccharide (LPS) at $7.5 \mathrm{mg} \cdot \mathrm{kg}^{-1}$ intravenously. This model mimicked human septic shock. The concentration of serum ST2 was examined using the mouse ST2 ELISA system. Serum ST2 were markedly elevated 12-24 h after LPS injection and rapidly declined at $48 \mathrm{~h}$.

monocytic leukaemia cell line [10]. Therefore, in the present in vivo models, we speculated that overexpressed plasma ST2 infiltrated the alveolar spaces, where it affected alveolar macrophages to suppress the production of cytokines, and subsequently suppressed the migration of neutrophils and increased vascular permeability.

In contrast, we did not detect any significant differences in BALF findings from day 3 after bleomycin treatment. It was speculated that the following aetiological explanations might account for the BALF findings from day 3: 1) ST2 could play an anti-inflammatory role only during the initial phase of the acute lung injury, and thus, could not stop the infiltration of inflammatory cells after 3 days; 2) ST2 overexpression in this system peaked at 12-24 h after gene transfer, and then ST2 rapidly declined (thus, the effects of ST2 would diminish along with attenuation of the plasma concentration of ST2); and 3) ST2 could cause adverse effects from day 3 after bleomycin treatment. In association with the second point, hydrodynamic gene transfer is certainly an invasive approach; and thus, repetitive transfer was difficult in our pilot study, because the mice were often dead by repeated injection. Therefore, a method for maintaining high ST2 levels even after $48 \mathrm{~h}$ of gene transfer must be developed to assess the effects of ST2 accurately in this model. In association with the third point, it was reported that serum ST2 was elevated in some autoimmune diseases [22], and ST2L has been reported to play an important role in the differentiation of T-helper (Th) cells, which induce the proliferation and activation of Th2 response [22, 23]. Furthermore, a recent study reported that recombinant ST2 boosted hepatic Th2 responses in vivo, increased Th2 cytokines and advanced liver fibrosis [24]. It suggests that ST2 protein plays an ambivalent dual role as follows: ST2 suppresses the production of pro-inflammatory cytokines from macrophages (anti-inflammatory effect), and conversely, ST2 stimulates the Th2 response (pro-inflammatory effect). Considering these reports, we hypothesised that overexpresssed-ST2 protein may affect lymphocyte proliferation in this model, which would cause the adverse effects from the increase of total cells seen after day 3 .

We found that endogenous ST2 mRNA and IL-33 were concurrently increased at day 3 after bleomycin treatment, whereas pro-inflammatory cytokines (TNF- $\alpha$ and IL-1 $\beta$ ) were increased immediately after bleomycin treatment. The effects of ST2 and IL-33 have been well investigated in allergic diseases; IL-33 is known to strongly induce the production of Th2 cytokines and IgE and increase the proliferation of eosinophils [6, 25]. TAJIMA et al. [8] reported that endogenous ST2 and Th2 cytokines (IL-4, IL-5) were slowly induced after bleomycin-treatment, similarly to our study. From these results, endogenous ST2, Th2 cytokines and IL-33 would affect the progress of lung injury following the initial phase of acute lung injury. It is thought to be important whether overexpressed-ST2 affects IL-33 production; however, we could not approach that problem because of the difficulty of keeping the high level of ST2 at day 3 after bleomycin treatment.

From day 7 after bleomycin treatment, pulmonary remodelling progressed, and we found subpleural collapse and an increase of collagen fibres rather than peribronchial accumulation of inflammatory cells. Around half of the bleomycin-treated mice and half of the mice treated with empty vector plus bleomycin died during days 7-14, suggesting that the pulmonary remodelling phase (days 7-14) was most responsible for mortality. In ST2-overexpressing mice, the histological findings and survival rate after bleomycin treatment were improved compared with other bleomycin-treated mice. Pulmonary remodelling was mostly caused by the degradation of extracellular matrix by neutrophils [26] and the initial increase of neutrophils plays a critical role in the progress of lung inflammation and fibrosis [27]. Considering the previous reports and our present data, we found that inhibiting the infiltration of neutrophils by ST2 at an early stage of lung 
injury helped to protect against proteolysis, minimised histological change and improved survival rates, even though the peribronchial inflammation, as indicated by the BALF findings, could not be completely suppressed.

In order to conclusively determine the roles of ST2, it will be necessary to conduct similar experiments using ST2 knockout (KO) mice. Although several studies using ST2 KO mice have been reported, unfortunately both specific soluble ST2 and transmembrane ST2L were absent in these mice, because the disrupted DNA of $\mathrm{KO}$ mice corresponds to a common portion of ST2 and ST2L [28]. Therefore, utilising available $\mathrm{KO}$ mice for the study of the involvement of ST2 in the lung inflammation would complicate the outcome. However, we speculate that previous results and the findings of the current study suggest that bleomycin would cause serious damage to the ST2-specific $\mathrm{KO}$ mice.

In conclusion, the present study confirmed that ST2 possesses the ability to suppress lung inflammation by inhibiting the elevation of pro-inflammatory cytokine levels and the accumulation of neutrophils, and by reducing vascular permeability. Further investigation into the aetiology of the effects of ST2 is required before the clinical applications are confirmed. However, ST2 could be a new candidate for the treatment of lethal acute lung injury.

\section{ACKNOWLEDGEMENTS}

The current authors would like to thank J. Miyazaki (Osaka University, Osaka, Japan) and T. Murakami (Jichi Medical Unfiversity, Tochigi, Japan) for providing plasmids and $\mathrm{T}$. Kasahara (Kyoritsu College of Pharmacy, Tokyo, Japan) for providing HEK293T cells. We also thank R. Izawa and M. Mato for excellent technical support, and K. Kishi (all Jichi Medical University) for advice on statistical analysis. N. Mato (Jichi Medical University) thanks Jichi Medical University for awarding this research the Young Investigator Award.

\section{REFERENCES}

1 Bedrossian CW. Iatrogenic and toxic injury. In: Dail DH, Hammar SP, eds. Pulmonary Pathology. New York, Springer-Verlag, 1988; pp. 511-517.

2 Ware LB, Matthay MA. The acute respiratory syndrome. $N$ Engl J Med 2000; 342: 1334-1349.

3 Tominaga S. A putative protein of a growth specific cDNA from BALB/c-3T3 cells is highly similar to the extracellular portion of mouse interleukin 1 receptor. FEBS Lett 1989; 258: 301-304.

4 Tominaga S, Kuroiwa K, Tago K, et al. Presence of expression of novel variant form of ST2 gene product in human leukemic cell line UT-7/GM. Biochem Biophys Res Commun 1999; 264: 14-18.

5 Schmitz J, Owyang A, Oldham E, et al. IL-33, an interleukin-1-like cytokine that signals via the IL-1 receptor-related protein ST2 and induces T helper type 2associated cytokines. Immunity 2005; 23: 479-490.

6 Brunner M, Krenn C, Roth G, et al. Increased levels of soluble ST2 protein and IgG1 production in patients with sepsis and trauma. Intensive Care Med 2004; 30: 1468-1473.

7 Oshikawa K, Yanagisawa K, Tominaga S, et al. ST2 protein induced by inflammatory stimuli can modulate acute lung inflammation. Biochem Biophys Res Commun 2002; 299: 18-24.

8 Tajima S, Oshikawa K, Tominaga S, et al. The increase in serum soluble ST2 protein upon acute exacerbation of idiopathic pulmonary fibrosis. Chest 2003; 124: 1206-1214.

9 Sweet MJ, Leung BP, Kang D, et al. A novel pathway regulating lipopolysaccharide-induced shock by ST2/T1 via inhibition of Toll-like receptor 4 expression. J Immunol 2001; 166: 6633-6639.

10 Takezako N, Hayakawa M, Hayakawa H, et al. ST2 suppresses IL-6 production via the inhibition of I $\mathrm{KB}$ degradation induced by the LPS signal in THP-1 cells. Biochem Biophys Res Commun 2006; 341: 425-432.

11 Leung $\mathrm{BP}, \mathrm{Xu} \mathrm{D}, \mathrm{Culshaw} \mathrm{S}$, et al. A novel therapy of murine collagen-induced arthritis with soluble T1/ST2. J Immunol 2004; 173: 145-150.

12 Takagi T, Yanagisawa K, Tsukamoto T, et al. Identification of the product of the murine ST2 gene. Biochim Biophys Acta 1993; 1178: 194-200.

13 Inoue S, Hakamata $Y$, Kaneko M, et al. Gene therapy for organ grafts using rapid injection of naked DNA: application to the rat liver. Transplantation 2004; 77: 997-1003.

14 Hakamata Y, Murakami T, Kobayashi E. "Firefly rats" as an organ/cellular source for long-term in vivo bioluminescent imaging. Transplantation 2006; 81: 1179-1184.

15 Howell DC, Johns RH, Lasky JA, et al. Absence of proteinase-activated receptor-1 signaling affords protection from bleomycin-induced lung inflammation and fibrosis. Am J Pathol 2005; 166: 1353-1365.

16 Kelley J, Newman RA, Evans JN. Bleomycin-induced pulmonary fibrosis in the rat. Prevention with an inhibitor of collagen synthesis. J Lab Clin Med 1980; 96: 954-964.

17 Lindenschmidt RC, Tryka AF, Godfrey GA, et al. Intratracheal versus intravenous administration of bleomycin in mice: acute effects. Toxicol Appl Pharmacol 1986; 85: 69-77.

18 Tajima S, Bando M, Ohno S, et al. ST2 gene induced by type 2 helper T cell (Th2) and proinflammatory cytokine stimuli may modulate lung injury and fibrosis. Exp Lung Res 2007; 33: 81-97.

19 Zhang G, Budker V, Wolff JA. High levels of foreign gene expression in hepatocytes after tail vein injections of naked plasmid DNA. Hum Gene Ther 1999; 10: 1735-1737.

20 Piguet PF, Collart MA, Grau GE, et al. Tumor necrosis factor/cachectin plays a key role in bleomycin-induced pneumopathy and fibrosis. J Exp Med 1989; 170: 655-663.

21 Jordana M, Richards C, Irving LB, et al. Spontaneous in vitro release of alveolar-macrophage cytokines after the intratracheal instillation of bleomycin in rats. Characterization and kinetic studies. Am Rev Respir Dis 1988; 137: 1135-1140.

22 Kuroiwa K, Arai T, Okazaki H, et al. Identification of human ST2 protein in the sera of patients with autoimmune diseases. Biochem Biophys Res Commun 2001; 284: 1104-1108.

23 Trajkovic V, Sweet MT, Xu D. T1/ST2 - an IL-1 receptorlike modulator of immune responses. Cytokine Growth Factor Rev 2004; 15: 87-95.

24 Amatucci A, Novobrantseva T, Gilbride K, et al. Recombinant ST2 boosts hepatic Th2 response in vivo. J Leukoc Biol 2007; 82: 124-132. 
25 Kurowska-Stolarska M, Kewin P, Murphy G, et al. IL-33 induces antigen-specific IL-5+ T cells and promotes allergicinduced airway inflammation independent of IL-4. J Immunol 2008; 181: 4780-4790.

26 Dunsmore SE, Roes J, Chua FJ, et al. Evidence that neutrophil elastase-deficient mice are resistant to bleomycin-induced fibrosis. Chest 2001; 120: 35S-36S.
27 Gasse P, Mary C, Guenon I, et al. IL-1R1/MyD88 signaling and the inflammasome are essential in pulmonary inflammation and fibrosis in mice. J Clin Invest 2007; 117: 3786-3799.

28 Townsend MJ, Fallon PG, Matthews DJ, et al. T1/ST2deficient mice demonstrate the importance of T1/ST2 in developing primary $\mathrm{T}$ helper cell type 2 responses. J Exp Med 2000; 191: 1069-1076. 